\title{
A time for reflection and thanks
}

Kian Keong Poh, FRCP, FACC

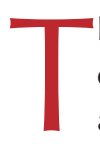

he change of year provides an opportunity for reflection on the Singapore Medical Journal (SM)'s progress in 2017 and the challenges ahead for 2018.

On the whole, the journal did well last year, achieving the targets that we had set. ${ }^{(1)}$ We saw a slight increase in impact factor (IF). Though the true impact of a journal cannot be solely measured by its IF, this is nonetheless an encouraging sign. It shows that our efforts to publish more high-quality research and comprehensive reviews, as well as making our works more relevant, searchable and citable, are paying off. We also saw an improvement in our manuscript turnaround time, which averaged around two months from submission to first decision and 3-5 months from acceptance to e-publication ahead of print. Our manuscript submission load also remained reasonably high, with a good mix of papers from Singapore and around the region. I am, as always, greatly indebted to our specialty editors, reviewers and editorial staff for their dedication, wise discussions, timely reviews and hard work - these results would not have been possible without them. In this issue, the $S M$ J acknowledges the many reviewers who have helped us to shape the journal in the past year (page 2).

2018 will continue to present its challenges. The fields of science and medicine are continually growing with new discoveries, ${ }^{(2)}$ more clinical trials and new, improved patient management strategies, and the number of new journals has expanded even more, including open-access journals with fast turnaround times and wide accessibility. Therefore, the SMJ must constantly evolve and keep up with the times to remain relevant. Yet, we also need to be careful not to sacrifice scientific rigour and quality for the sake of speed and expediency. To this end, we have maintained a strict, double-blinded peer-review process to prevent bias in the review process. In addition, we have joined the CrossRef community since 2013, incorporating Turnitin as part of our submission checks for plagiarism and duplicate submissions, and assigning digital object identifiers (i.e. DOls) to all our published articles to make them easy to find, cite, link and access. We have also revamped the $S M$ / website to give it a more updated look and to make it more accessible and reader-friendly.

We implemented some new initiatives last year. When authors submit their manuscripts to the $S M$ J via Editorial Manager, they will now be able to include their Open Researcher and Contributor ID (ORCiD), a 16-digit persistent digital identifier that distinguishes the author from other researchers. ${ }^{(3)}$ We encourage all authors to make use of this new function to help track their research outputs more effectively. In addition, we are now working with Crossref to enable Cited-by, a function that informs authors when their work is being cited in other content. We hope that our authors will find these new initiatives beneficial.

As I assume my third two-year term as Chief Editor of the $S M$ J, I wish to thank the President and Council Members of the Singapore Medical Association for the endorsement, trust and editorial independence that they have given my editorial team and I. Our past editor, Prof C Rajasoorya, rightly pointed out that "independence, however, comes with accountability and responsibility - to deliver what is desirable for the readership". ${ }^{(4)}$ This responsibility - to not only our readers but also our authors and the medical community at large - is not to be taken lightly. Lastly, on a personal note, I am grateful to my SMJ predecessor, Prof Teo Eng Kiong, and my lifetime mentor, the late Prof Chia Boon Lock, for their astute guidance and stellar support over the years. The editorial board will strive to continually improve on our shortcomings while maintaining a high standard of scientific integrity, as we work toward making $S M$ J the journal of choice for local and overseas researchers and readers.

\section{REFERENCES}

1. Poh KK. Moving forward in the new year. Singapore Med J 2017; 58:1.

2. Loh JP, Poh KK. Changes in the practice of cardiology: therapies at the forefront of science. Singapore Med J 2016; 57:344-6.

3. ORCiD. Available at: https://orcid.org/. Accessed December 14, 2017.

4. Rajasoorya C. Metamorphosis of the Singapore Medical Journal - where do we go from here? Singapore Med J 2002; 43:1-4. 